FSS

Okun, S., \& Nimrod, G. (2020). Online religious counseling for older adults. Cyberpsychology: Journal of Psychosocial Research on Cyberspace, 14(4), Article 7. https://doi.org/10.5817/CP2020-4-7

\title{
Online Religious Counseling for Older Adults
}

\author{
Sarit Okun ${ }^{1} \&$ Galit Nimrod ${ }^{1,2}$ \\ 1'Department of Communication Studies, Ben-Gurion University of the Negev, Israel \\ ${ }^{2}$ The Center for Multidisciplinary Research in Aging, Ben-Gurion University of the Negev, Israel
}

\begin{abstract}
Studies have demonstrated the importance of online activities to wellbeing, especially in later life. The present study seeks to determine whether and how online religious counseling can improve the wellbeing of older believers. A six-month qualitative study was conducted with a group of Orthodox Jewish older adults $(N=26$, aged 70-96) who manifest various types of age-related distress. The participants were home trained to use a dedicated, accessible online platform featuring religious questions and answers (Q\&A). Data were collected through netnographic observation, monthly online inquiry and in-depth interviews with counselees and counselors alike. Analysis indicated that online spiritual Q\&A for the elders are characterized by unique content, types and styles of discourse. Their variety reflects the heterogeneity of needs, areas of interest and worldviews among older religious adults. Participation in online religious counseling provided them with numerous religious, intellectual and social rewards. At the same time, their counselors-six rabbis that volunteered in this project-gained religious, communal, professional and psychological benefits from the opportunity to share their knowledge and advice. Anonymity, asynchronicity, digital literacy and types of questions were identified as issues that may have opposite effects on the experiences of participants and counselors, respectively. Although some factors may delay and/or diminish positive contributions, involvement in online religious counseling appears to promote wellbeing in later life. This service is particularly beneficial to Orthodox older adults with detrimental health conditions whose use of online religious Q\&A helps them cope with the difficulties they face and maintain their enjoyment of life.
\end{abstract}

Keywords: Old age; online counseling; Q\&A; religion; spirituality; wellbeing

\section{Introduction}

To date different aspects of 'religion' and 'spirituality' have been examined in the academic literature, with sometimes the two terms describing the same essence and sometimes each term represents a different meaning. The present study is based on the approach that does not separate the terms, claiming that 'spirituality' contains elements of religious behavior, and that 'religion' also includes aspects of spirit, faith and the search for the sublime (Hsiao et al., 2008; Koenig, 2012). Either way, both are perceived as multidimensional, dependent on different situations and contexts, and changing over time and circumstances (Pargament, 2002).

In line with the approach that does not separate spirituality from religiosity, spiritual wellbeing was defined as a satisfactory relationship with a transcendent deity and contact with one's inner being, as well as interaction and association with the religious community and environment (Fisher, 2011). Many studies have shown the importance of religion for spiritual wellbeing, especially in later life (e.g., Lifshitz et al., 2019; Malone \& Dadswell, 2018; Shaw et al., 2016). Towards the end of their lives, people undertake religious involvement in the pursuit of physical healing, comfort and strength (Wang et al., 2014). The positive influence of older adults' participation in spiritual activities and religious groups is expressed as reinforced faith, greater sense of purpose and meaning in life, spiritual and tangible support, positive thinking, improved emotional wellbeing and more overall social capital 
that strengthens them physically and spiritually (Malone \& Dadswell, 2018; Shaw et al., 2016). Although such benefits are expressed primarily when older adults face debilitating health conditions (Litwin et al., 2017), participation in formal religious activities tends to decline with advancing age and deteriorated health (Wang et al., 2014). Consequently. older adults' daily spiritual needs are often poorly met, leaving their religious concerns unresolved (Ahmad et al., 2015).

The onset of the COVID-19 pandemic made such spiritual distress relevant to many other older adults, regardless of their health condition. Places of prayer (mosques, synagogues and churches) closed down, and many of the religious elders all over the world, who were previously regular attendees at religious activities, were ordered to stay home and/or self-quarantined and could no longer maintain their spiritual routine. This situation may have impacted their mental and spiritual wellbeing. Furthermore, as studies showed that support for the religious and spiritual needs of elders is no less important than finding solutions for their physical and material needs (Levin, 2013; Levin \& Prince, 2011), the reduced participation in religious activities may have influenced the older believers' health.

Relying on media and religion studies, this study suggests that it is possible to assuage such difficulties by training older adults to use online religious services. This suggestion is explored by focusing on online religious counseling in a Questions and Answers (Q\&A) format- a practice that is very common among religious populations. While this format has already been examined in previous research (e.g., Steinitz, 2011; Tsuria, 2016; Tsuria \& Cambell, 2020), its use by older individuals was never explored. Besides examining older users of such online counseling services (i.e., the counselees), the study also explored the experiences of the spiritual scholars who provide such counseling (i.e., the counselors). The reason for that was twofold: First, counseling is a communicative process that involves two parties and thus in order to gain in-depth understanding of it one should explore all its components. Second, comprehending the challenges faced by the counselors may improve the online religious counseling services offered to the older generation. Accordingly, this research sought answers to three interrelated questions:

1. What characterizes the contents of online spiritual counseling in Q\&A format for religious older adults?

2. To what extent does involvement in online religious counseling affect older counselees, and how?

3. To what extent does involvement in online religious counseling for older adults affect the counselors, and how?

These questions were examined through a case study of Orthodox Jewish older adults residing in Israel, who were trained to use a dedicated religious Q\&A website with the rabbinical leaders of their community (the term rabbis/rabbinical describes spiritual leaders or religious teachers in Judaism).

\section{Literature Review}

As the internet has become more integrated in everyday life, the number of online platforms linked to spiritual and religious activities has increased (Campbell \& Golan, 2011). Such growth has generated academic interest in exploring the relationship between religion and new media, leading to an increasing number of studies on the topic (Tsuria, 2016). Early studies in this field examined online spiritual engagement as 'lived religion,' a prominent sociological approach that focuses on the experiences of religious individuals in everyday life (Hall, 1997; Orsi, 2003). Later, Campbell (2012) used the concept of 'networked religion' to explain how religion shifts and expands when situated in a technological space and digital culture. Similarly, Hoover and Echchaibi (2012) discussed the blurring boundaries between 'offline religion' and 'online religion,' defining the latter as third spaces of socialreligious interactions. Currently, the most common term among scholars in this field is "digital religion," which refers to religion being performed via technology or an internet platform (Campbell, 2017). Overall, digital religion studies offer "a focused microcosm for identifying broader trends in how digital technology can be used to satisfy individual and communal social and communicative needs" (Campbell, 2017, p. 5).

\section{Online Religious Counseling}

Online counseling for religious individuals is a common spiritual practice on the internet. This phenomenon began to appear, along with other types of Q\&A websites, as online information sources became more available and users developed an increasing tendency to consult with web-based resources in their quest to fill various 
informational needs (Wong et al., 2015). The accessibility and availability of online spaces led to the emergence of websites with 'ask-a-scholar' sections, offering guidance to people confronting various religious dilemmas. Unlike online religious communities, online counseling services invite everyone to ask questions, but answers are entrusted only to experts, typically authorities in the relevant field (Wong et al., 2015).

Kawabata and Tamura (2007) described several types of online counseling for religious people: Advice or religionbased discussion between believers and non-believers; religious professionals engaged in spiritual mediation who attract new believers or help struggling people; spiritual spaces where people suffering hardships and difficulties can gather, as well as worship services. They also found that online religious counseling requires internet skills, time and labor. Moreover, it creates a new form-or forms-of the religious group's activities and organizational structure. Nevertheless, according to Abdel-Fadil (2015), there has been very little scholarly documentation and analysis of forms of online religious counselling services.

\section{Online Jewish Religious Counseling}

Jewish religious communities negotiate new media in various ways (Cohen, 2015), including the formation of "local spaces"-webpages, blogs or web portals specific for their communities (Tsuria \& Cambell, 2020). Since the end of the 20th century, one of the most prominent form of digital religious activity is online 'Responsa'-a Jewish tradition of rabbinical questions and answers (Q\&A) (Tsuria \& Cambell, 2020). This digital practice reflects a positive response to the internet within modern Orthodox communities (Cohen, 2015) and became quite popular in the Orthodox Jewish world (Tsuria \& Cambell, 2020).

Although relatively new to the online sphere, the practice of Q\&A has a long tradition in Judaism and it is considered a prominent religious activity in the Orthodox sector (Steinitz, 2011; Tsuria, 2016). Since the eighth century CE, responsa became an integral part of the Halakhic (Jewish religious law) system of scholarly inquiry and Bible study, that identifies the permitted and the prohibited and establishes preferred ideals and accepted performance. Religious Judaism has always encouraged the believing public to ask questions and challenge existing paradigms. This enabled rabbis to recognize challenges and deal with difficulties arising from changing times and/or distress conditions, making the responsa dominant in the development of Halakha and its constant renewal. Once the responsa has been documented in writing, it became part of the Halakhic scholarship and theoretical corpus (Glick, 2006). Although the main function of the responsa is to rule Halakha, this practice also allows for theological Q\&A, such as clarification, annotation and refinements in Jewish thought (Glick, 2006). In this sense, the responsa is a spiritual activity not only because some of the believers' questions are intended to cover issues of faith, soul and worldview (as a kind of spiritual counseling), but also because all religious observance of the commandments is meant to lead to spiritual awakening and inner work on the human psyche.

Over the years, there have been various channels of responsa, including dedicated classes at synagogues, faceto-face conversations with rabbis, special sections in the press, telephone conversations, fax, TV shows and more recently emails and mobile phone text messages. The historical role of personal counseling, however, seems to have been replaced gradually by public Q\&A websites (Glick, 2006). "Ask the rabbi" websites offer Q\&A with the rabbinical leaders or chat services on a variety of topics, from Jewish law to life choices. Usually, the questioners can post the question anonymously or reveal their identifying details, knowing that some of the questions and answers are published publicly on the website. While many in the Jewish community are pleased with such access to rabbis and the reach and magnitude of Torah study, others are concerned that this type of Responsa is hurting the Halakhic discourse and belittling rabbinical authority (Tsuria \& Cambell, 2020).

According to Steinitz (2011), using the internet to "ask the rabbi" has several advantages, of which the first is accessibility. The internet allows users from all over the world to consult with esteemed spiritual leaders, regardless of their geographic location. Second, users enjoy relative anonymity, allowing them to pose delicate questions that they would probably not dare ask in frontal encounters. Third, as online Q\&A are typically archived, previous discussions can be examined so that users learn from the experience of others. Online responsa also allow the rabbis more time to find answers, as well as an unprecedented opportunity to disseminate their agendas throughout the world. 
The availability and anonymity of online responsa, however, also enable behaviors considered inappropriate, such as sending the same question to several rabbis and selecting the most convenient response. Furthermore, certain rulings are intended for individuals under particular circumstances only, but their online publicity makes them appear to be guidelines for all. Ignorance of context may arouse contempt towards responsa in particular and Halakhic rulings in general (A. Katz, 2015). In addition, using digital communication for practices such as responsa can impact understandings of religious authority (Tsuria \& Cambell, 2020).

A review of the literature on digital responsa shows that scholars in this field acknowledge the fact that it is a complicated process influenced by the users' questions, the rabbis' answers (Steinitz, 2011) and the media themselves (Gottesman, 2009; Nachtstern, 2008). Tsuria and Campbell (2020) recently studied the rabbinic authority in digital responsa in light of the ongoing tension in Judaism between tradition and modernity. They argued that online religious Q\&A represent a case of fusion between new media and the religious tradition of responsa in way that allows rabbis to negotiate their rabbinical authority. On the one hand, a growing need for online presence makes the quantity of answers an important part of constructing rabbinical authority online. On the other hand, however, extensive online activity in rabbinical Q\&A effects the length and depth of the answers. These trends result in a reframing of the rabbi's roles and the Halakhic discourse itself.

\section{Online Counseling for Older Adults}

Older persons experience common concerns and challenging circumstances that are often intertwined, such as retirement, death of spouse and friends and decreased mobility and independence. Counseling is a useful and supportive intervention therapy for those nearing the end of their life span (Koltz et al., 2016), but counselors should be well versed in the physical, mental and emotional aspects of their older counselees and adept at clinical diagnoses specifically applicable to them (Blando, 2011). Although this population has historically underused counseling services, there is a gradual increase in the number of elderly persons changing their attitudes towards counseling and seeking such services (Koltz et al., 2016).

The aging of the world's population and the increasing availability of online information sources has led to growth in the popularity of Q\&A websites among older internet users (Wong et al., 2015). Furthermore, studies show that online counseling is capable of replicating the facilitative conditions and positive impacts of face-to-face encounters (Richards \& Viganó, 2013). Research on online counseling services for religious minorities or for older people is lagging behind, however (Flasch \& Fulton, 2019). This phenomenon should arouse concern because many old persons throughout the world consider themselves religious and are likely to insert their spiritual identity and values into any counseling relationship (Keller, 2014). Moreover, according to Flasch and Fulton (2019), research on spiritual counseling must consider the cultural milieu in which it is provided. This highlights the need for further investigation into the role of religious involvement in promoting positive aging for older adults from different cultures and societies. Accordingly, considering the location of the present study, this article focuses on Orthodox Jewish older adults residing in Israel.

\section{The Present Study}

The literature mentioned above suggests that online religious counseling for older adults may offer some solution for the spiritual distress that many of them feel. Nevertheless, no study published to date examined the contribution of online religious Q\&A to senior citizens and/or the experiences of their counselors. Focusing on the case study of Orthodox Jewish older adults residing in Israel, the present study thus aimed to explore the manner and the extent to which involvement in online religious Q\&A for this population affects the counselees as well as the Orthodox Jewish Rabbis that serve as their counselors. The study filled gaps in the body of knowledge and identified a simple solution to what appears to be a significant problem among the growing population of older individuals.

\section{Methods}

The study was based on a mixed-methods approach in which in-depth interviews, netnographic observations and online questioning were applied with a group of 26 Orthodox Jewish older adults with age-related mobility 
difficulties, who were trained to use an exclusive online religious counseling website in responsa format. All the participants in this study were affiliated with the Israeli National-Religious community, a group also referred to as simply religious, Modern Orthodox, or religious Zionists (Y. Katz, 2012). This community is associated with the ultra-Orthodox community, which often rejects modernity and new media (Tsuria \& Cambell, 2020). The study participants were also long time members of the Religious Kibbutz Movement (RKM) in Israel—a nationalist, Zionist organization whose members live in communes based on the values associated with "Torah VeAvodah" (religiosity and labor). Although these adults lived in supportive religious communities, the study focused on individuals within such communities suffering from physical conditions preventing them from leaving their homes, which in turn leads to spiritual and social distress.

Spiritual distress in later life was identified in the literature, but was also discussed in a social seminar of the RKM organization and confirmed by study participants in the initial in-depth interviews. To improve their religious wellbeing, a new online platform of responsa was developed, specifically designed for older Orthodox users. Six Orthodox rabbis volunteered to participate in this digital religious venture, providing expert Halakhic response to the participants' questions for a period of one month each. After the institutional review board at the authors' university examined and approved the study, all participants were trained personally at their homes to use this online religious counseling and acquired experience with it over a six-month period (from November 2017 to May 2018). They chose their own usernames and were instructed to use the online Q\&A service at least once a week.

\section{Participants}

Study participants were 26 Orthodox persons aged 70-96 originating in Israel's Jewish sector, 13 women and 13 men. All were retired, yet 12 volunteered at their previous workplace or for various projects on a weekly basis. The majority were married but nine were widowers and one lost her spouse during the study (there were no singles or divorced). Fourteen were born in Israel, and the rest immigrated from different countries in the world (Eastern European mostly). All participants had age-related mobility difficulties: 18 of them traveled around their locality with a "mobility scooter" (electric vehicle and mobility aid equivalent configured like a motorscooter) and two used a wheelchair. All participants also reported various health conditions such as diabetes, high blood pressure, and decreased vision and hearing. Three were hospitalized during the study period due to health difficulties.

The criteria for participation were retirement, age 70 and over, possession of home computer with internet connection, experiencing age-related mobility difficulties, feeling spiritual distress because of these limitations and/or interest in enriching one's spiritual world, cognitive ability to acquire new online skills and willingness to participate in a study that could take up to one year (although its actual duration was six months). Initial recruitment was supported by the third age coordinators in the various RKM communities and completed by snowball sampling. Evaluation of participants' suitability for the study included testing their physical functioning according to the Activities of Daily Living and Mobility checklist (Noelker \& Browdie, 2013) and evaluating their cognitive competence according to the short version of the Mini-Mental State Examination questionnaire (Folstein et al., 1975). Their religious needs were explored extensively in the initial interview by questions relating to identity, faith, spiritual activity and the extent to which their current religious needs are met, for example: How do you define yourself religiously? In what manners your religious belief is manifested in your daily life? In what religious activities are you currently involved? Are there activities you cannot attend, and, if so, what are they, why can't you attend them, and how do you feel about it? Do you consult with a rabbi on matters of responsa? If not - why, and if so - when, where, with whom, and how does it affect you? To protect the participants' privacy the pseudonyms that they have used in the Q\&A were maintained in this report, with each participant's age and gender noted parenthetically.

Six rabbis were recruited to volunteer in the study. To recruit them for the research, we sent emails to all RKM rabbis as well as to a number of other rabbis from the national-religious sector in Israel. In the emails we explained the rationale of the project and asked them to volunteer for one month. Ten rabbis expressed their agreement to participate, and eventually six of them answered the participants' questions. All rabbis were community leaders at the time of the study, except for one who has already retired. Although their identity was known to the study participants, their names were concealed in this report to protect their privacy. 


\section{The Responsa Platform}

A website with Q\&A section was constructed especially for this study with the help of an expert in the field of open code. It was administrated as a pilot website and served as a 'digital laboratory' because it could only be used by the study participants, the programmer and the researchers. The website was designed in a manner making it accessible to the older age group and designated for older adults in the orthodox religious sector in Israel. The name given to the site was "70 Faces of the Torah," which is a well-known phrase in Hebrew describing the many different ways to serve God. The number 70 also hints at the website target audience's age. In addition, much thought was invested in the design of the website and its suitability for the elderly users, including the selection of the font and its size, pictures, colors and technological interfaces. Pressing the 'queries' icon on the website's main menu (See Figure 1) led users to the Q\&A section where questions could be asked, and previous questions and answers were also accessible. Participants could access their own queries as well as those asked by others.
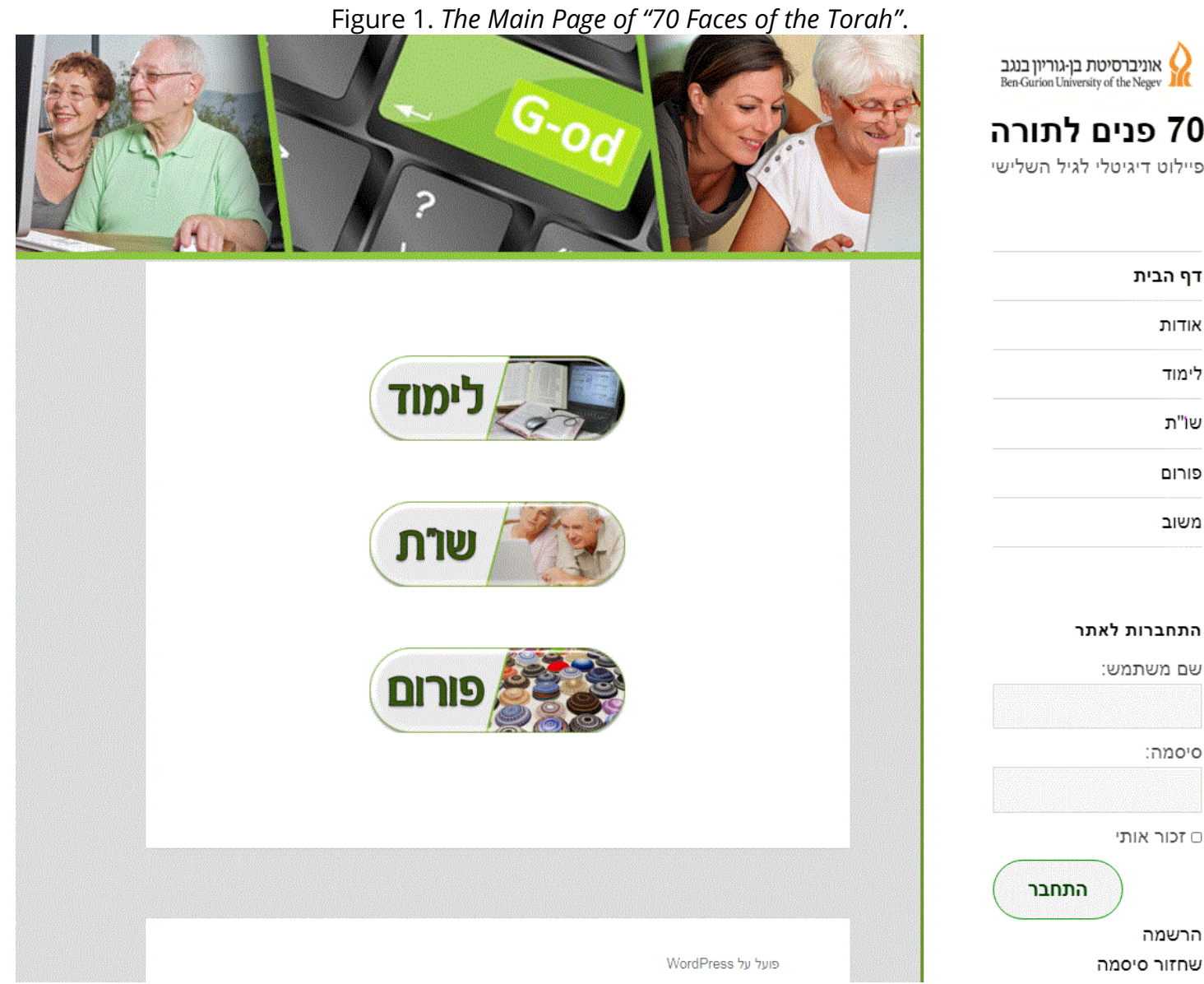

Notes. The menu includes three options 'study, 'queries' and 'forum'. The queries icon led users to the Q\&A section. (Inquiries regarding the other sections are reported in separate articles.)

\section{The Training Procedure}

After construction of the trial website and recruitment of the study participants, training began. This step included one or two personal sessions at the older adults' homes, during which the participants learned how to use the Q\&A interface offered on the designated website. The training sessions, lasting 60-120 minutes, were coordinated in advance by phone with each of the participants and recorded by a tape recorder. At the beginning of the session, the participants were asked to select a nickname, which preserved their anonymity on the website. We helped them register their nickname and password, showed them how to submit a question to the rabbis through the website, and how to see if the online action was taken. In the last part of each training meeting, participants had the opportunity to experience the online platform themselves with our gentle guidance and reminders of the different topics discussed earlier that day. At the end of meeting, participants received a summary with explanations regarding the contents of that meeting. In many cases, training meetings went beyond one or two sessions, with added home visits and telephone guidance. Hence, in some cases basic training sessions were not enough and a prolonged process of guidance and support was required. Additionally, many participants "took 
advantage" of the training sessions to seek assistance in other matters related to computer and internet use (e.g., uploading photos from a mobile phone, locating and recovering lost Word files).

\section{Data Collection}

Four qualitative data collection methods were incorporated in the study:

(1) In-depth, semi-structured interviews (60-180 minutes) with study participants before and at the end of the study (total $=52$ ), audiotaped and transcribed verbatim. The in-depth interviews conducted at the beginning of the study provided information about the study participants' physical limitations, spiritual needs, and sense of wellbeing. The concluding interviews allowed us to examine whether and how participants' wellbeing improved as a result of their participation in the study. At the end of the study, in-depth interviews were also conducted with the volunteer rabbis. Some of these interviews were face-to-face and some were done via telephone calls. The interviews lasted an average of 45 minutes, and example questions are: What were your expectations before volunteering to this project? Was your experience similar to the expectations, and if not, how? Were you surprised by the older adults' questions, and if so, why? Did you get any direct feedback from them? Can you point at the strengths of this online platform and/or share issues that can be improved? The rabbis' responses provided new and original perspectives on the present study and its results, thereby enriching existing understanding of digital religion

(2) Netnographic observations (2-3 weekly online observations throughout the study period, each about 60-120 minutes long): The netnographic observations were an important tool in identifying the characteristics of the responsa. They enabled recognizing which study participants were posting questions, when and how they posted them, and what they were asking. This method also facilitated identification of the characteristics of the rabbis' answers.

(3) Monthly email messages to participants, containing a short, self-administered questionnaire was designed to improve the user experience. One hundred and thirty such questionnaires were sent to the participants (first 5 months $\times 26$ participants), of which 78 were answered and returned. Primarily, the monthly reports directed the changes made to the online counseling platform during the study period. For example, some participants drew our attention to the fact that there was no visual difference between an answered question and a pending question. Following the comments on this topic, icons were added: a red button signified an unanswered question, and a green button signified an answered question.

(4) Informal telephone conversations and WhatsApp text communications with the participants were also important sources of information.

\section{Data Analysis}

Data analysis was based on the principles of Grounded Theory (GT) (Corbin \& Strauss, 1990). GT has several methodological genres representing extensions and developments of the original GT. Although the original goal of traditional GT is to generate a conceptual theory that accounts for the studied population, the newer genres rely on its principles for the analysis of symbolic experiences and meanings (c.f., Foley \& Timonen, 2015; Tie et al., 2019). In this sense, therefore, GT is a "structured, yet flexible methodology" (Tie et al., 2019, p. 2).

As required in GT, data were collected and analyzed simultaneously throughout the study, and involving constant transitions between the online contents observed in the Responsa website and the written and verbal reports provided by the counselees and the counselors. This principle enabled using the findings related to the contents in the summarizing interviews with the study participants. Analysis was facilitated by using the Atlas.ti 8 software and followed the three GT coding stages (Ralph et al., 2014): The open coding stage included an in-depth reading of all protocols, along with generation of codes based on concepts, similarities and reoccurrences in the data. Next, axial coding involved reorganizing the data according to all sources of information in a manner that added, subtracted, expanded or reduced codes, categories and themes as required. In this study, this stage also involved clarification and/or renaming of certain codes: As some of the codes we have used were expressions in Hebrew 
or quotations from the Jewish sources that were difficult to translate into English, they were replaced with short labels that we constructed as we interacted with the data.

The first two coding procedures were conducted by the first author and then reviewed by the second author. In the rare cases of disagreements between the authors, differences were discussed and adjudicated. The final selective coding stage was conducted together and included finding the connections among the different categories in a particular logical sequence and identifying the story line that the data created. Relying on our discussions of how the various categories fit together and reflect symbolic experiences and meanings related to the online responsa, this stage involved writing the storyline using detailed descriptions of the findings.

The GT method was selected based on the understanding that analysis of data in a study that uses several collection techniques requires a dominant and central element of triangulation-a key component of GT. Indeed, analysis of the data in this study included systematic cross-referencing among the various sources of information, constant comparison strategies and repeated reflexivity (Corbin \& Strauss, 1990). These techniques called for shifting back and forth between preliminary sub-groupings and revised versions, as well as ongoing comparisons among different participants and circumstances. Reflexive and theoretical notations, as well as team discussions, were used to refine the analysis and shape interpretations (Ralph et al., 2014).

\section{Results}

Data analysis pointed to four principal findings: The characteristics of online responsa for older adults, the rewards older persons derived from participation in this spiritual practice, the rabbis' benefits from this activity and the contradictory experiences that accompanied participation in online religious counseling. Figure 2 presents a detailed illustration of the findings, reflecting the comprehensive structure of each main finding and the associations among them.

Figure 2. A Graphic Illustration of the Results.

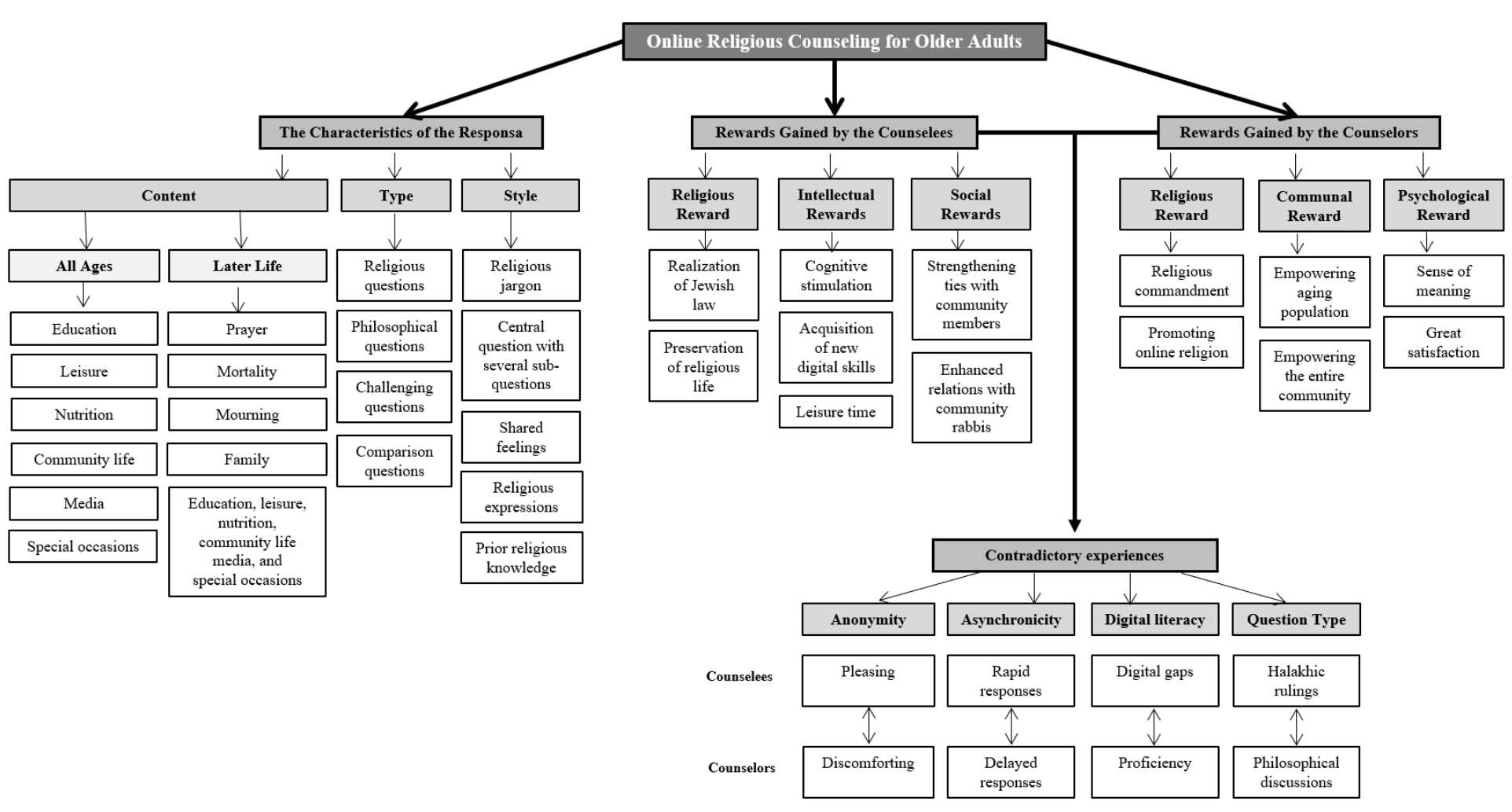

\section{Characteristics of Online Responsa for Older Adults}

The characteristics of the online responsa studied were classified into three aspects of Q\&A: 'Content,' 'type,' and 'style'. 


\section{The Responsa's Content}

The 'content' of the responsa, as could be expected, dealt with the Jewish-religious way of life. It was discovered, however, that about half the issues examined were religious matters affecting Jews of all ages, while the remainder focused on religious affairs relevant only to later life. All responsa, multi-age and age-specific alike, covered a variety of topics.

Responsa related to all ages dealt with education, nutrition, media, leisure, special occasions and community life. Hagar (76, woman), for example, asked what blessing to recite before eating cranberries ("Blessed be... the Creator of the fruit of the earth [vegetables]" or "... the fruit of the tree [fruits]"). Zipora (75, w), like the previous participant, posed many Halakhic questions related to all ages, including: "Is organ donation perceived as a commandment in the Torah?" The religious issues relevant only to later life dealt with similar topics, but focused primarily on prayer, health, mortality, mourning and family. For example, Zriha $(82, w)$ asked: "I use Nordic walking poles to develop my muscles. May I walk with them on the Sabbath?" [According to the Jewish religion, it is forbidden to exercise on the Sabbath (Friday night to Saturday night) except if instructed to do so by a medical professional]. The rabbi's negative response was accompanied by quotations from Jewish sources. He explained that "Sabbath has to be different in all aspects of life: Food, drink, clothing, speech and even how we walk. Therefore, on the Sabbath it seems appropriate to refrain from exercise in all its forms."

\section{The Types of the Responsa}

Four chief domains were identified regarding the 'type' of responsa: Philosophical, challenging, comparison and religious practice questions. The first type, philosophical questions, usually consisted of an attempt to clarify the theoretical aspects of a particular area of religious life. Chatula $(95, w)$, for example, asked: "Why do people wash their hands ritually when leaving a cemetery without reciting a blessing?" Challenging questions, the second type, usually opened with an expression of protest regarding a particular matter and continued with a request for the rabbi's opinion about it. For example, Shaked (80, man), began his question with a defiance of the children noise during prayer in his synagogue. Afterwards, He asked the rabbi to write his opinion and tell whether this problem exists in other communities. This example also illustrates the third type, comparison questions, as in many responsa the questioners referred to specific religious dilemmas by comparing places, ages or rabbis' opinions. The last and most dominant type of content was religious practice questions. These included inquiries such as "Does the Halakha permit...," "What is the religious ruling on the matter of..." or "Is there a religious prohibition against...". Noah (78, $\mathrm{m})$, for example, asked: "My wife received a scooter from the clinic because she broke her leg. Can she use the scooter on Sabbath or do we need to take her in a wheelchair? What is the explanation for this ruling?"

\section{The Style of the Responsa}

Analysis also identified five 'style' qualities: All questions used religious jargon and expressions; in many of them, older adults shared feelings about the religious dilemma presented. Most questions were based on prior religious knowledge and published as a central question with several sub-questions. In addition, a significant number of questions were presented as someone else's dilemma. A question posted by Savta-Mentos $(74, \mathrm{w})$ may illustrate several of these characteristics:

My neighbor asked me whether a small pool for grandchildren near the house could be used on the Sabbath. We know people who find it jarring because it detracts from the sacred atmosphere of the Sabbath, but I'm not sure it's a Halakhic prohibition. I would be happy to know whether there is a difference between Yom Tov [major religious holidays] and the Sabbath and between private and public places regarding this issue and if so, why?

Mapping the characteristics of the online responsa shed light on the unique aspects of this specific religious platform - a designated channel for spiritual matters relevant to later life in particular. The study showed that online, anonymous responsa incorporating Q\&A content heterogeneity, types and styles-and thereby enabling presentation of an issue in a variety of formats and perspectives-can serve as a space for older believers. 


\section{The Benefits of Online Responsa to Older Adults}

Participants reported three principal rewards resulting from their online responsa use: 'Religious,' 'intellectual' and 'social' benefits.

\section{Religious Benefits}

The first, 'religious' benefits, included what study participants described as the website's greatest contribution: Facilitating realization of Jewish law and preservation of religious life. Philips $(71, \mathrm{~m})$ explained it as follows: "As a believer who adheres to the religious way of life, it was an excellent opportunity to read various Halakhic rulings." A similar claim was presented by Meir $(72, \mathrm{~m})$ : "This was far more successful than any online responsa I have known to date. I'm guessing that's because I connect, trust and sympathize more with the Halakhic rulings of the religious kibbutz rabbis. They are serious scholars."

Many participants explained that the Q\&A also strengthened their sense of direction in life, as expressed by Shikma (71, w):

I don't know if it can be argued in an informed and unequivocal way that religious law queries [which is the central anchor of the Q\&A] are the ones that help me deal with the difficulties in my life, but I think so. They help me reduce the question marks on a daily basis and provide clear and decisive answers.

Another example of this benefit was provided by Zipora (77, w): “I'm almost deaf. In the Halakha lessons in the synagogue I hear nothing. From that aspect, questions and answers on the internet can certainly make a practical contribution to my life." Kinor $(79, \mathrm{~m})$ also explained it: "For me, the great importance of the Q\&A is not to make me a more religious person, but to be assisted by rabbis in making religion more practical!" His words intensified focus on the significance of cautious, meticulous observance of daily religious practices in the lives of elderly Orthodox Jews.

\section{Intellectual Benefits}

Another major reward consisted of 'intellectual' gains that may be divided into three categories. The first, cognitive stimulation, is exemplified by Chad-ayin $(72, \mathrm{~m})$ : “The responsa were great. What I enjoyed most was using the text for further study of religious precepts, either on my own or with Rabbi Google's assistance." For Tamar (76, m), some religious answers were too short but "that left space for thought. Sometimes it has spurred me to continue to look for more sources on the subject."

The second was acquisition of new digital skills, as indicated by Lippi $(72$, w): "How can I not do [online] things that children do easily every day? So I started [with the online responsa] and was pleasantly surprised. It's much less complicated than I thought." Tuli's $(76, \mathrm{~m})$ computer had many technical problems that made it difficult for him to use the online counseling, and probably restricted other online activities as well. We contacted a technician to fix the problems. Tuli acknowledged the "overhaul" of the computer and the internet connection, saying that "I had learned how to use online responsa and by the way solved my computer problems; or vice versa."

Furthermore, online responsa were considered a more beneficial use of leisure time, as Tzvia $(73, w)$ described: "I'm sure this [online responsa] can expand horizons; it would be useful for people who waste their time doing pointless things." Dvash $(74, \mathrm{w})$ expressed a similar idea:

I have free time to do lots and learn new things. I really love Jewish ceremonial art, such as crocheting kippot [also known as a "yarmulke," the head covering traditionally worn by religious Jewish men], prayer shawls, hair coverings worn by religious Jewish women, etc... so if I spend my time on the internet, I prefer to focus on matters of faith and Halakha. 


\section{'Social' Benefits}

The third benefit reported was 'social,' described in terms of strengthening ties with community members and enhanced relations with community rabbis. Some study participants perceived the responsa as a social project, as explained by Anonymous (73, m): "I'm satisfied with my life, especially when I'm busy with community affairs. It's an activity that combines both socializing and religion." Tzivoni $(82, \mathrm{w})$ expressed a similar claim:

I have to admit that over the years I have become less involved in religious Q\&A. Nevertheless, I liked it [the online counseling platform] given that this is a RKM activity that connects people and rabbis with values I very much identify with.

The social pleasure of reading religious Q\&A was also highlighted by Zipora $(77, \mathrm{w})$ : "It was interesting to read what other people of my age were asking. I enjoyed comparing what happens in other families and kibbutzim."

The enhanced relations with community rabbis, which was also described as a social benefit, was expressed by participants who found the online platform a convenient opportunity to establish further dialogue with the leaders of their religious communities. Tuli, for example, $(76, \mathrm{~m})$ explained: "I respect and appreciate our rabbi, but I liked the opportunity [in the online responsa] to check the rulings of other rabbis, who are still from 'our' communities." The digital religious consulting also offered emotional support to some participants, primarily widowers, as expressed by Dvash $(74, \mathrm{w})$ : "The rabbi of our community is the most charming person in the world! Usually, I feel comfortable asking him about Halakhic matters, but I am happy with any other way to approach him."

Overall, analysis showed that the online responsa supported faith, strengthened a sense of direction in life, enriched intellectual knowledge, developed thought and added value to leisure time. In the same manner, they allowed for religious-communal involvement and social interaction with community spiritual leaders. Participants in this study emphasized the positive potential of this activity, suggesting that the current intervention did not reach its full potential.

\section{The Benefits of Online Responsa to Rabbis}

The positive effects were not limited to older adults alone, as data analysis also identified four rewards that the rabbis gained from volunteering for the online responsa project: 'Religious,' 'communal,' 'professional' and 'psychological' rewards.

\section{'Religious' Reward}

The most significant contribution reported, the 'religious' reward, expressed two complementary spiritual aspects. First, the rabbis perceived the responsa as a religious commandment and emphasized the moral responsibility to support older adults in every way possible, both online and offline. They corroborated their view by quoting verses from the sources, such as: "Do not discard me in my old age, do not forsake me when my strength fails" (Psalms, 71:9), or "Stand up in the presence of the aged, show respect for the elderly and revere your God" (Leviticus, 19:32).

The second aspect was the rabbis' satisfaction with promoting online religion among older adults through the responsa platform. Their principal argument declared that older people are legally entitled to retire from work, but they must not quit the 'observance of religious precepts'. Both religious aspects were expressed by Rabbi A.:

The internet is a convenient tool for transmitting religious information to community members... responsa cannot replace the personal contact between the rabbi and his community, but it can help older people just as much as young people in reading and studying of Halakhic law.

These aspects were also emphasized by Rabbi B., who wrote an e-mail at the end of the research period offering to expand older adults' online activities:

I would also suggest another online initiative [on religious issues]: Once a week everyone will sit in front of computers in their homes and listen to or watch an online lesson, including the opportunity 
to ask questions and participate. If anyone misses the live lesson, he/she can watch its recording at any convenient time. It should be taken into account that these people may have difficulty accessing the lesson website at the exact time and raise questions. Overall, however, it is a very sophisticated method that manages to place people in different parts of the world in one lesson, and the RKM seniors can enjoy it because they also know each other.

\section{'Communal' Reward}

The second contribution reported was 'communal,' as the rabbis considered responsa activity to be a social mission that may empower the aging population and the entire community, as Rabbi B. indicated: "Loneliness is the most difficult problem in old age. In this context, I think that the responsa website constitutes a salient instrument with which a rabbi may foster trust and social contact within his community." The communal reward was also evident in Rabbi D.'s comment: "I encourage our community members to schedule Torah learning times in every way possible. From that perspective, online responsa is another good way to generate social discourse within the religious life framework."

\section{'Professional' Reward}

The rabbis also reported a 'professional' reward associated with having a useful new means for doing the work they are supposed to do. Rabbi E., for example, claimed:

One of the key roles of a rabbi in the community is the responsa. Apart from the [religious] sermons, lessons, and the social issues, he must teach Halakha, steer the public in a Halakhic-practical manner and respond to the community members in a more personal and private setting. From this point of view, the online religious Q\&A provides a solution for people in my community who do not feel comfortable interacting face-to-face or calling.

The 'professional' reward identified was also reflected in improved practical ability to provide rapid Halakhic responses to old adults, as explained by Rabbi E.:

The online responsa are excellent as 'first aid' in the Halakhic realm. It's like turning to the internet for medical advice: Usually the person gets a short and quick online answer, but the doctor tells him to come to the clinic the next day for continued treatment. Similarly, the responsa are excellent first aid in the Halakhic realm; but full religious counseling requires a more personal, lengthy and profound encounter.

\section{'Psychological' Reward}

Finally, a reward of a more 'psychological' nature was reported only by the one retired rabbi participating in the project, who experienced great satisfaction and a sense of meaning. It was evident that online religious consulting enabled him to put his extensive accumulated knowledge and experience to good use. In the concluding interview with him, he said:

The modern notion that life is mostly conducted from the age of 20 to the age of 60 is Spartan and laconic. The religious response is that every person, of any age, and at any given moment has an important role in the religious life, and it never ends. The challenges never end, and it is always possible to continue to contribute and grow spiritually. The attitude that in later life we should be a bit idle is fundamentally wrong. The older person has many spiritual tasks both within the family and in the community! I get up every morning with that idea in mind.

These four rewards proved that rabbis could derive significant benefits from offering online religious counseling to older people. The volunteers appeared to have thoroughly enjoyed their ability to fulfill the religious duty of helping the aging population and making online religion part of their daily lives. Similar to the older adults, the rabbis in this study emphasized the potential of this practice, suggesting that the project's inherent advantages were not fully realized. 


\section{Contradicting Experiences}

During the research period, it became increasingly clear that four factors exerted opposite effects on counselees and counselors, respectively: 'Anonymity,' 'asynchronicity,' 'digital literacy' and 'types of questions'.

\section{Anonymity}

Most participants were pleased with 'anonymity,' while the rabbis expressed moral and professional discomfort. Tamar $(76, \mathrm{~m})$ claimed that anonymity was necessary: "I deliberately gave myself a woman's name and formulated my questions in the feminine gender. I do not want to be recognized when people try to guess who wrote this or that question." Zriha $(82, \mathrm{w})$ presented a similar argument: "Some people turn to the local rabbi [for responsa], but I do not feel comfortable doing so for all sorts of reasons, but on the anonymous website it felt comfortable and pleasant."

In contrast, Rabbi A. said: "I do not like anonymity because it allows people to hide important information and limits my ability to help them." The disadvantage of anonymity was also reflected in a written post previously published by Rabbi B. in one of the religious websites featuring an 'ask-a-scholar' section:

In some cases, anonymity is very problematic. A Halakhic answer is not 'automatic' because the same question will have a different answer depending on the background, the questioner and the circumstances. An answer given to John Doe does not necessarily fit Jane Doe.

\section{Asynchronicity}

Another factor was 'asynchronicity'. The older adults were uncomfortable with the asynchronous nature of the online communication and expected the rabbis to provide them with rapid responses. Most rabbis, however, were working full time, so their responses were delayed. Tzivoni $(82, \mathrm{w})$, for example, said her experience was excellent "except for the slow posting of the answers." This problem was also mentioned in Hagar's $(76, w)$ summarizing report:

You have to think about how to make the Q\&A quicker, because there have been a few instances where it took too long for an answer to be received. For example, once I posted a question regarding Hanukkah [a Jewish holiday] and got the answer only after the holiday was over.

The rabbis were aware of this problem, as Rabbi C. explained: "Unfortunately, because of my workload, I could not answer the questions more quickly."

\section{Digital Literacy}

'Digital literacy' engendered different experiences as well. Most older adults were not very familiar with digital technologies, as Kinor $(79, \mathrm{~m})$ noted: "I don't understand this gadget at all." The rabbis, by contrast, were very knowledgeable and excited about using technology in the service of Judaism. Among others, this argument was presented by Rabbi E.:

In general, the web helps me a lot in Halakhic rulings and in [religious] learning - searching and finding sources, writing lessons, preparing presentations and also in the printing service... Through the internet I also talk and consult with other rabbis and hear their opinions. Indeed it is a very effective and useful tool. Also in the aspect of Torah study - the internet is very productive! But we must remember that it is not the main thing but just an addition

\section{Types of Questions}

The last such factor identified concerned 'types of questions'. Before the project began, the rabbis asked to have the new platform focus primarily on thought-based discussions rather than Halakhic rulings. Rabbi E., for example, 
wrote in an email exchange: "What is the point of asking a rabbi a Halakhic question if he is in charge [of spiritual affairs] at another kibbutz [where the counselee does not live]?" In practice, however, the older adults requested religious rulings frequently, such as: "Is it permissible to send an email before Sabbath to a place where Sabbath has already entered?" [According to religious law, ICT use is not allowed on Saturday] or "We have an aquarium. Should the fish food be changed before Passover [Jewish holiday] because of the 'ban on chametz'?" [According to Halakha, chametz is any food containing leavening agents, which are prohibited on Passover].

The conflicting experiences observed intensified understanding and brought the insights of the previous findings into sharper focus. On the one hand, the activity's characteristics reflected an impressive scope of participation and the experiences of the older adults and the rabbis appeared positive. On the other hand, however, the differences in perception between rabbis and older adults seemed to limit the scope and intensity of the benefits they derived.

\section{Discussion}

The mix of qualitative methods applied in this study expanded existing knowledge about online religious counseling while emphasizing the value of such service to older adults. First and foremost, the findings indicated that online religious Q\&A for elders are characterized by a variety of contents, question types and styles. The observed distinction between Q\&A of interest to people of 'all ages' and those relevant only to 'later life' supports the portrayal of religious activity as multidimensional (Lifshitz et al., 2019) and corroborates the claim that older people's involvement in religious each aspect is likely to vary and may change with age (Wang et al., 2014).

These content variations are closely linked to the four types of online religious questions identified. The observed Q\&A in all four categories (philosophical, challenging, comparison and religious practice) underscored the heterogeneous spiritual needs of older adults with regard to areas of interest and worldview alike. Their abundance and diversity are consistent with Glick's claim (2006, p. 2): "Although responsa literatures does [sic] primarily address practical issues of Jewish law, viewed in its entirety, it is wider than the ocean." Furthermore, the five dominant styles revealed in this study reinforce previous findings. The use of religious jargon, feelings and expressions, together with participants' reliance on previous knowledge, yield a hybrid language and unique spiritual content similar to those of Ultra-Orthodox Jewish forums (Okun \& Nimrod, 2017). Moreover, the presentation of one's concerns as someone else's dilemma echoes the covert style applied by internet users who solicit health information at social Q\&A websites (Wong et al., 2015).

One major finding of this study is its identification of the three benefits for older adults. Similar to the positive influence on psychological wellbeing identified in research on offline spiritual activities among Israeli Jews (Levin, 2013), it was evident that online religious counseling can be an important and empowering practice in later life, leading to spiritual growth, intellectual development and social connectedness. As Litwin and colleagues (2017) found, this spiritual involvement may be particularly significant for individuals with age-related mobility constraints, as it keeps them connected with community and spiritual life, providing them with a sense of empowerment, stability, support and direction and improving their emotional wellbeing during critical times (Malone \& Dadswell, 2018).

Exploring the contribution of online religious counseling to the counselors revealed a host of spiritual, communal, professional and psychological benefits. Each of the rewards demonstrates the positive attitude of the rabbis towards digital communication as a significant channel for spiritual work. Their reports indicate that they have long recognized and used the internet's enormous potential for religious and professional purposes. This finding fits well with the claims of Baker and Ray (2011), who maintained that consulting professionals recognize the digital channel as an unprecedented opportunity to treat people with difficulties (such as individuals from disadvantaged populations). According to Flasch and Fulton (2019), counselors' interventions correspond with the values, beliefs and cultural nuances of their counselees. As such, the positive experiences of the Orthodox rabbis participating in this study concerned their involvement in online responsa that were adapted pragmatically and specifically for a designated group of Orthodox older adults.

The rewards identified in this study reinforce the findings of Tsuria and Campbell (2020) about the role of the online responsa in the Israeli National-Religious community-Provide halakhic expertise, psychological advice and 
theological leadership. In line with their research, the present study emphasizes that this religious practice does not threaten the rabbis' authority or reduce their role and presence in the lives of older community members. Our research, however, adds to Tsuria and Campbell's findings regarding the impact of the rabbis' extensive involvement in online activity on the length and depth of their answers. Apparently, religious older believers are slightly disturbed when the length and depth of the answers do not meet their expectations.

Despite the positive experiences of all parties involved, the study also identified four factors with opposing impacts. The observed dissimilar perceptions of anonymity emphasized previous findings regarding the gap between counselors and their counselees. According to Kawabata and Tamura (2007), the latter enjoy the digital interface that hides their identities because it allows them to express themselves more clearly and openly. By contrast, even if counselors appreciate the advantages of anonymous counseling, it is difficult for them to ascertain their counselees' condition adequately. Asynchronicity was another contradictory factor: Counselees expected rapid response, but effective online counseling inevitably demands devotion of considerable time and effort to reading incoming messages carefully and crafting replies meticulously (A. Katz, 2015). A similar gap has been identified with respect to digital literacy: The counselees were all elders and probably deficient in digital skills (Kawabata \& Tamura, 2007), while their rabbinic counselors were shown to have mastered the necessary skills.

The last issue in dispute concerned types of questions. Although elderly people are assumed to have accumulated considerable religious knowledge, they maintain interest in discussing Halakhic issues. Conversely, as suggested by Glick (2006), the rabbis' idea of focusing on philosophical matters may originate in the requirement abjuring religious teachers to exercise constant discretion and extreme caution to avoid misrepresentation of Halakha.

The four contradictory experiences described above may have somewhat reduced the amount and quality of the benefits acquired by participating older adults and rabbis. As such, addressing them before and during the project may enhance the special qualities of online responsa and augment their contribution to spiritual wellbeing in later life. This service may be particularly beneficial to Orthodox older adults with detrimental health conditions (Litwin et al., 2017) who use online religious counseling as a coping mechanism, helping them maintain their quality and enjoyment of life.

\section{Limitations and Future Research}

Despite the scope and depth of the findings this study displayed limitations that render follow-up research essential. First, even though the homogeneity of the research group was a distinct advantage, it is important to remember that this is a qualitative study and therefore its findings cannot be generalized. It will thus be appropriate to examine the points of view expressed by believers from other religious milieus and a wider range of ages. The information about other religious groups' online motivations, habits and behaviors will enrich the literature in the field and support the development of online religious platforms for those populations.

Second, the online responsa platform designed for this study was suitable for desktop computers only. Although a considerable amount of research has been conducted on the topic of online counseling via mobile devices (e.g., Ardi \& Sukmawati, 2019; Lee et al., 2012; Sukmawati et al., 2019), innovation in mobile apps often ignores the needs and limitations of older users, thereby distancing them from new technologies (Ahmad et al., 2015). Accordingly, the study's questions should also be applied to Q\&A services for older adults offered on smartphones.

Third, the fact that all participants were of the Religious Kibbutz Movement can be understood as a limitation because those older adults enjoy extensive support from their communities (Koltz et al., 2016). The opposite, however, can also be true. If a case study that constitutes older kibbutz members showed such positive results, it is reasonable to assume that online religious counseling will have even greater impact on the wellbeing of lonely older adults.

The reality created by the COVID-19 pandemic rendered the insights generated by this study quite significant to believers of all faiths. The digital religion, in general, and the online religious counseling, in particular, offer such believers an important supplementary channel for their religious needs and lifestyle. To optimize the benefits for older believers, however, such individuals should be exposed to a variety of digital religion opportunities as early 
as possible. Training sessions in their own homes and continuous support may increase lonely and homebound senior citizens' spiritual satisfaction, and the earlier the better.

\section{Acknowledgements}

This work was supported by grants to the first author from Kreitman's school of advanced graduate studies at BenGurion University of the Negev, Israel; Ageing + Communication + Technologies (ACT) - a research project funded by the Social Sciences and Humanities Research Council of Canada and housed at Concordia University in Montreal, Canada; and Yad Tabenkin - the research, ideological and documentary center of the Kibbutz Movement in Israel. The institutional review board at the authors' university examined and approved the study. Approval number is 17-6-101.

\section{References}

Abdel-Fadil, M. (2015). Counselling Muslim selves on Islamic websites: Walking a tightrope between secular and religious counselling ideals? Journal of Religion, Media and Digital Culture, 4(1), 1-38.

https://doi.org/10.1163/21659214-90000099

Ahmad, N. A., Zainal, A., Razak, F. H. A., Adnan, W. A. W., \& Osman, S. (2015). User experience evaluation of mobile spiritual applications for older people: An interview and observation study. Journal of Theoretical and Applied Information Technology, 72(1), 76-85. http://www.jatit.org/volumes/Vol72No1/9Vol72No1.pdf

Ardi, Z., \& Sukmawati, I. (2019). The contribution of social media and mobile application to individual subjective well-being in counseling perspective. Journal of Counseling and Educational Technology, 2(1), 39-47.

https://doi.org/10.32698/0571

Baker, K., \& Ray, M. (2011). Online counseling: The good, the bad, and the possibilities. Counselling Psychology Quarterly, 24(4), 341-346. https://doi.org/10.1080/09515070.2011.632875

Blando, J. (2011). Counseling older adults. Routledge.

Campbell, H. A. (2012). Understanding the relationship between religious practice online and offline in a networked society. Journal of the American Academy of Religion, 80(1), 64-93. https://doi.org/10.1093/jaarel//fr074

Campbell, H. A. (2017). Religious communication and technology. Annals of the International Communication Association, 41(3-4), 228-234. https://doi.org/10.1080/23808985.2017.1374200

Campbell, H. A., \& Golan, O. (2011). Creating digital enclaves: Negotiation of the internet among bounded religious communities. Media, Culture \& Society, 33(5), 709-724. https://doi.org/10.1177/0163443711404464

Cohen, Y. (2015). Israeli rabbis and the internet. In H. A. Campbell (Ed.), Digital Judaism: Jewish negotiations with digital media and culture (pp. 183-204). Routledge.

Corbin, J. M., \& Strauss, A. (1990). Grounded theory research: Procedures, canons, and evaluative criteria. Qualitative Sociology, 13(1), 3-21. https://doi.org/10.1007/BF00988593

Fisher, J. (2011). The four domains model: Connecting spirituality, health and well-being. Religions, 2(1), 17-28. https://doi.org/10.3390/rel2010017

Flasch, P., \& Fulton, C. L. (2019). Counseling Jewish Americans: Considerations for practice. Counseling and Values, 64(1), 2-19. https://doi.org/10.1002/cvj.12091

Foley, G., \& Timonen, V. (2015). Using grounded theory method to capture and analyze health care experiences. Health Services Research, 50(4), 1195-1210. https://doi.org/10.1111/1475-6773.12275 
Folstein, M. F., Folstein, S. E., \& McHugh P. R. (1975). "Mini-mental state": A practical method for grading the cognitive state of patients for the clinician. Journal of Psychiatric Research, 12(3), 189-198.

https://doi.org/10.1016/0022-3956(75)90026-6

Glick, S. (2006, June 13). The contribution of responsa literature to the study of halakha, Jewish culture and history. The Schechter Institutes, Inc. https://schechter.edu/the-contribution-of-responsa-literature-to-the-studyof-halakha-jewish-culture-and-history/

Gottesman, Y. (2009). A new direction to Halachic questions and answers: The compatibility of Responsa topics to the internet medium, regarding sexuality and attitudes towards the internet [Unpublished master's thesis]. Bar Ilan University.

Hall, D. D. (Ed.). (1997). Lived religion in America: Toward a history of practice. Princeton University Press.

Hoover, S. M., \& Echchaibi, N. (2012). The "third spaces" of digital religion [Discussion paper]. https://www.researchgate.net/publication/287644204_The_Third_Spaces_of_Digital_Religion

Hsiao, A. F., Wong, M. D., Miller, M. F., Ambs, A. H., Goldstein, M. S., Smith, A., Ballard-Barbash, R., Becerra, L. S., Cheng, E. M., \& Wenger, N. S. (2008). Role of religiosity and spirituality in complementary and alternative medicine use among cancer survivors in California. Integrative Cancer Therapies, 7(3), 139-146.

https://doi.org/10.1177/1534735408322847

Katz, A. (2015). Drachim chadashot leshu"t (telephone, internet vehodaut)-yitronot, chesronot vemaskanot. [New ways of responsa (telephone, internet and messaging) - pros, cons and conclusions]. The Mayan, 55, 56-62.

https://www.machonso.org/uploads/images/212-16-56-62.pdf

Katz, Y. (2012). Technology use in the religious communities in Israel: Combining traditional society and advanced communications. Journal of Religion, Media \& Digital Culture, 1(2), 1-30.

https://doi.org/10.1163/21659214-90000014

Kawabata, A., \& Tamura, T. (2007). Online-religion in Japan: Websites and religious counseling from a comparative cross-cultural perspective. Journal of Computer-Mediated Communication, 12(3), 999-1019. https://doi.org/10.1163/21659214-90000014

Keller, R. R. (2014). Religious diversity in North America. In P. S. Richards \& A. E. Bergin (Eds.), Handbook of psychotherapy and religious diversity (pp. 21-50). American Psychological Association.

Koenig, H. G. (2012). Religion, spirituality, and health: The research and clinical implications. ISRN Psychiatry, 2012, Article 278730. https://www.hindawi.com/journals/isrn/2012/278730/

Koltz, R. L., Tarabochia, D. S., Wathen, C. C., Koltz, D. J., Foote, A., Cuyle, N., \& Volkman, A. (2016, March). Living well into later years: A psychoeducational support group [Paper presentation]. American Counseling Association Conference, Montreal, Canada. https://www.counseling.org/docs/defaultsource/vistas/article_15e3bf24f16116603abcacff0000bee5e7.pdf?sfvrsn=7da9442c_4

Lee, U., Kang, H., Yi, E., Yi, M., \& Kantola, J. (2012). Understanding mobile Q\&A usage: An exploratory study. In CHI '12: Proceedings of the SIGCHI Conference on Human Factors in Computing Systems (pp. 3215-3224). ACM. https://doi.org/10.1145/2207676.2208741

Levin, J. (2013). Religious behavior, health, and well-being among Israeli Jews: Findings from the European Social Survey. Psychology of Religion and Spirituality, 5(4), 272-282. https://doi.org/10.1037/a0032601

Levin, J., \& Prince, M. F. (2011). Judaism and health: Reflections on an emerging scholarly field. Journal of Religion and Health, 50, 765-777. https://doi.org/10.1007/s10943-010-9359-2 
Lifshitz, R., Nimrod, G., \& Bachner, Y. G. (2019). Spirituality and wellbeing in later life: A multidimensional approach. Aging \& Mental Health, 23(8), 984-991. https://doi.org/10.1080/13607863.2018.1460743

Litwin, H., Schwartz, E., \& Avital, D. (2017). Religiosity and wellbeing among older Jewish Israelis: Findings from SHARE. Journal of Religion, Spirituality \& Aging, 29(2-3), 208-223. https://doi.org/10.1080/15528030.2015.1132491

Malone, J., \& Dadswell, A. (2018). The role of religion, spirituality and/or belief in positive ageing for older adults. Geriatrics, 3(2), Article 28. https://doi.org/10.3390/geriatrics3020028

Nachtstern, B. (2008). Judaism 2.0: The influence of the internet on the religious society in the 21 st century. In Rashi, T., \& Zept, M. (Eds.), Yiahadut vemedia [Judaism and media] (pp. 195-208). Golden Crown.

Noelker, L. S., \& Browdie, R. (2013). Sidney Katz, MD: A new paradigm for chronic illness and long-term care. The Gerontologist, 54(1), 13-20. https://doi.org/10.1093/geront/gnt086

Okun, S., \& Nimrod, G. (2017). Online ultra-orthodox religious communities as a third space: A netnographic study. International Journal of Communication, 11, 2825-2841.

https://ijoc.org/index.php/ijoc/article/view/6515/2085

Orsi, R. A. (2003). Is the study of lived religion irrelevant to the world we live in? Journal for the Scientific Study of Religion, 42(2), 169-174. https://doi.org/10.1111/1468-5906.t01-1-00170

Pargament, K. I. (2002). The bitter and the sweet: An evaluation of the costs and benefits of religiousness. Psychological Inquiry, 13(3), 168-181. https://doi.org/10.1207/S15327965PLI1303_02

Ralph, N., Birks, M., \& Chapman, Y. (2014). Contextual positioning: Using documents as extant data in grounded theory research. SAGE Open, 4(3). https://doi.org/10.1177/2158244014552425

Richards, D., \& Viganó, N. (2013). Online counseling: A narrative and critical review of the literature. Journal of Clinical Psychology, 69(9), 994-1011. https://doi.org/10.1002/jclp.21974

Shaw, R., Gullifer, J., \& Wood, K. (2016). Religion and spirituality: A qualitative study of older adults. Ageing International, 41(3), 311-330. https://doi.org/10.1007/s12126-016-9245-7

Steinitz, O. Z. (2011). Responsa 2.0: Are Q\&A websites creating a new type of halachic discourse? Modern Judaism 31(1), 85-102. https://doi.org/10.1093/mj/kjq034

Sukmawati, I., Ardi, Z., Ifdil, I., \& Zikra, Z. (2019). Development and validation of Acceptability of Mental-Health Mobile App Survey (AMMS) for android-based online counseling service assessments. Journal of Physics: Conference Series, 1339(2019), Article 012124. https://doi.org/10.1088/1742-6596/1339/1/012124

Tie, Y. C., Birks, M., \& Francis, K. (2019). Grounded theory research: A design framework for novice researchers. SAGE Open Medicine, 7. https://doi.org/10.1177/2050312118822927

Tsuria, R. (2016). Jewish Q\&A online and the regulation of sexuality: Using Foucault to read technology. Social Media + Society, 2(3). https://doi.org/10.1177/2056305116662176

Tsuria, R., \& Campbell, H. A. (2020). "In my own opinion": Negotiation of rabbinical authority online in responsa within Kipa.co.il. Journal of Communication Inquiry. Advance online publication.

https://doi.org/10.1177/0196859920924384

Wang, K. Y., Kercher, K., Huang, J. Y., \& Kosloski, K. (2014). Aging and religious participation in late life. Journal of Religion and Health, 53(5), 1514-1528. https://doi.org/10.1007/s10943-013-9741-y 
Wong, N. M. N., Chu, S. K. W., Huang, H., \& Hung, M. Y. (2015). Cross-cultural quality comparison of online health information for elderly care on Yahoo! Answers. Proceedings of the American Society for Information Science and Technology, 51(1), 1-10. https://doi.org/10.1002/meet.2014.14505101055

\section{Correspondence to:}

Sarit Okun

Department of Communication Studies, The Faculty of Humanities and Social Sciences

Ben-Gurion University of the Negev

P.O. Box 653

Beer-Sheva 84105

Israel

Email: sarit.okun(at)post.bgu.ac.il, sarit.okun(at)gmail.com

Editorial record: First submission received on October 27, 2019. Revisions received on September 14, 2020 and November 4, 2020. Accepted for publication on November 5, 2020.

Editor in charge: Lenka Dedkova

\section{About Authors}

Sarit Okun, PhD, just graduated from the department of communication studies, at Ben-Gurion University of the Negev, Israel. She is also a research fellow in the school of social work at Bar-Ilan university, Israel. Her research deals with digital religion and its contribution to the wellbeing of different population groups.

Galit Nimrod, Ph.D., is full professor at the Department of Communication Studies and a research fellow at the Center for Multidisciplinary Research in Aging at Ben-Gurion University of the Negev, Israel. Aiming to contribute to the understanding of wellbeing in later life she studies psychological and sociological aspects of leisure, media and technology use among older adults. 